\title{
Confectionery consumption in childhood and adult violence
}

\author{
Simon C. Moore, Lisa M. Carter and Stephanie H. M. van Goozen
}

\section{Summary}

Diet has been associated with behavioural problems, including aggression, but the long-term effects of childhood diet on adult violence have not been studied. We tested the hypothesis that excessive consumption of confectionery at age 10 years predicts convictions for violence in adulthood (age 34 years). Data from age 5, 10 and 34 years were used Children who ate confectionery daily at age 10 years were

Childhood factors that influence the expression of violence in adulthood are numerous and include economic, ecological and individual factors (such as personality traits). ${ }^{1}$ Diet has been causally associated with population mortality rates, neurocognitive deficits, disruptive behaviour, antisocial and aggressive behaviour, and offending behaviour in a prison population. ${ }^{2-5}$ Furthermore, decision biases, such that rewards are subjectively overweighted and punishment underweighted, are associated with delinquency. ${ }^{6}$ Confectionery (sweets/chocolates), often used as a quick reward for children, has also received attention, ${ }^{3,7}$ although studies have mostly focused on the short-term effects of diet on behaviour: the long-term effects have yet to be determined. The objective of our study was to extend what is currently known about childhood risk factors for violence by also considering the role of confectionery. We hypothesise that excessive confectionery consumption increases the likelihood of violence in adulthood.

\section{Method}

Our analysis included data on the births and families of babies (respondents, hereafter) born in the UK in one particular week ( $n=17415)$ derived from the British Cohort Study which began in 1970. Information was requested on all babies born (alive or dead) after the 24th week of gestation from 00:01 on Sunday 5th April to 24:00 on Saturday 11th April 1970. It is estimated that not more than $5 \%$ and not less than $2 \%$ of all births were missed. Since 1970 there have been seven data collections designed to monitor respondents' health, education, social and economic circumstances. These additional waves took place when respondents were aged $5,10,16,26,30,34$ and 42 years. We used data from the age 10 wave when respondents were asked how frequently they consumed confectionery, and the age 34 wave, when self-report violent offending data and additional information on socioeconomic status were collected. Additional data were taken from the age 5 wave that characterised respondents' early development, including parenting style. Respondents were coded positive for perpetration of violence (violence, hereafter) if the most recent offence, between the age 30 and age 34 surveys, for which they were found guilty involved violence. Violence data were collected using a reliable self-report computer-assisted interview methodology. ${ }^{8}$

Confectionery consumption was reduced to a binary variable (every day $=1$, less often or never $=0$ ) owing to small numbers in the violence variable. To check the robustness of estimates we regressed confectionery consumption onto violence and then incrementally added control variables. With no substantial change significantly more likely to have been convicted for violence at age 34 years, a relationship that was robust when controlling for ecological and individual factors.

\section{Declaration of interest}

None.

in either the sign or significance of the effect of eating confectionery, we then sought the most parsimonious model by removing control variables that yielded no significant association. Numerous control variables were entered into initial models, including information on: the child's behaviour at home at age 5 years and maternal circumstances based on the Rutter A Scale of behavioural deviance (completed by a parent, usually the mother, and designed to measure behaviour-adjustment problems) and the Malaise Inventory (a 24-item self-completion scale designed to assess psychiatric morbidity) ${ }^{9}$ aggression and impulsivity at age 10 years, assessed by the child's class teacher; mental ability at age 5 years, derived from figure drawing and vocabulary tests, reduced to a single mental ability score using a procedure described by Batty ${ }^{10}$ and validated against a health visitor's subjective assessment of ability. Forty-three questions were used to assess parental attitudes in the age 5 wave and iterated principal factor analysis with an oblique rotation method $^{11}$ (Kaiser-Meyer-Olkin measure of sampling adequacy 0.88 ) yielded three factors: an authoritarian attitude to parenting, mothers' perceptions of their rights, and a parenting style that is more liberal and affords children greater freedom. Across all models the association between eating confectionery daily remained statistically significant. As the binary outcome variable, violence, is a rare event $(0.47 \%)$ and the statistical analysis of rare events $(<5 \%)$ presents problems, particularly for logistic models, ${ }^{12}$ a rare event logistic model ${ }^{12}$ with cluster correction on government office region was the preferred analytic strategy.

\section{Results}

Overall, $69 \%$ of respondents who were violent by the age of 34 years reported that they ate confectionery nearly every day during childhood, compared with $42 \%$ who were non-violent. Table 1 presents statistics from the final regression model. Tests for collinearity in independent variables yielded variance inflation factors less than 1.05. Spearman correlation coefficients suggested weak ( $\rho<0.1$ and $P<0.001$ for each comparison) positive associations between being male and not having educational qualifications after the age of 16; eating confectionery daily and being male; access to motorised transport at the age of 34 and being male; parents' attitudes towards parenting and eating confectionery daily; access to motorised transport at 34 years; and living in a rural area at age 34 years. Weak negative associations between living in a rural area at age 34 years and eating confectionery daily $(\rho=-0.06)$, and parents' attitudes towards parenting and access to motorised transport at age 34 


\begin{tabular}{|c|c|c|c|c|}
\hline Variable & Wave & Odds ratio & $95 \% \mathrm{Cl}$ & $P$ \\
\hline Daily confectionery consumption & 10 years & 3.182 & $1.374-7.369$ & 0.007 \\
\hline Male & 5 years & 8.927 & $2.526-31.549$ & 0.001 \\
\hline Late birth & 5 years & 3.648 & $1.531-8.692$ & 0.003 \\
\hline Health visitor screening & 5 years & 0.294 & $0.096-0.9$ & 0.032 \\
\hline Child-oriented parenting & 5 years & 1.874 & $1.319-2.661$ & $<0.001$ \\
\hline Access to a motor car & 34 years & 0.224 & $0.11-0.456$ & $<0.001$ \\
\hline Rural area & 34 years & 1.801 & $0.977-3.321$ & 0.059 \\
\hline Constant & & 0.003 & $0-0.022$ & $<0.001$ \\
\hline
\end{tabular}

years $(\rho=-0.03)$ were also observed. Marginally more substantial associations were observed between not having educational qualifications after the age of 16 and eating confectionery daily $(\rho=0.11)$, and parents' attitudes towards parenting and not having educational qualifications after the age of $16(\rho=0.12)$.

The rare events logistic regression model (Table 1) yielded a significant relationship between eating confectionery at age 10 years and violence at age 34 years. This association was consistent across all models where ecological, childhood and other controls were included. Other significant relationships between control variables and violence included a child's gender and parents' attitudes towards parenting. Health visitor screening during childhood protected against adult violence. Having access to motorised transport at age 34 years protected against adult violence, whereas living in a rural area at age 34 years increased the risk of violence. Attrition and non-response bias mean that the data available for analysis may not be characteristic of the larger population, which might affect our conclusions.

\section{Discussion}

Analysis of the British Cohort Study has the advantage of a large sample size and the opportunity to control for numerous potential confounds. However, as a general population cohort study it was not designed to specifically examine the nature of diet and how it might be related to behaviour in the long-term. Exogeneity, whereby a third unmeasured variable promotes both dietary choice and violence across the lifespan (e.g. a genetic factor), is unlikely because dietary choices for 10 -year-olds are primarily governed by their immediate circumstances, in particular their parents and primary carers, and these factors are already accounted for in the model presented here. Moreover, self-report data provide an accurate source of behavioural information ${ }^{8}$ and having controlled for numerous control variables suggest that the relationship between confectionery consumption and violence is both novel and robust.

Candidate mechanisms linking confectionery consumption to adult violence must account for enduring changes into adulthood. One plausible mechanism is that persistently using confectionery to control childhood behaviour might prevent children from learning to defer gratification, in turn biasing decision processes towards more impulsive behaviour, biases that are strongly associated with delinquency. ${ }^{6}$ Furthermore, childhood confectionery consumption may nurture a taste that is maintained into adulthood, exposing adults to the effects of additives often found in sweetened food, ${ }^{3}$ the consumption of which may also contribute towards adult aggression. Moreover, although parental attitudes were associated with adult violence, the effect of diet was robust having controlled for these attitudinal variables. Irrespective of the causal mechanism, which warrants further attention, targeting resources at improving childhood diet may improve health and reduce aggression.

Simon C. Moore, PhD, Violence and Society Research Group, Applied Clinica Research and Public Health, School of Dentistry, Cardiff University; Lisa M. Carter School of Medicine, Cardiff University; Stephanie van Goozen, PhD, School of Psychology, Cardiff University, UK

Correspondence Simon C. Moore, Violence and Society Research Group, Applied Clinical Research and Public Health, School of Dentistry, University of Cardiff, Cardiff CF14 4XY, UK. Email: mooresc2@cardiff.ac.uk

First received 13 Nov 2008, final revision 30 Apr 2009, accepted 1 Jun 2009

\section{Funding}

The research was supported by a grant from the Economic and Social Research Council (ES/D000483/1).

\section{References}

1 Farrington DP. Early predictors of adolescent aggression and adult violence. Violence vict 1989; 4: 79-100.

2 Gesch CB, Hammond SM, Hampson SE, Eves A, Crowder MJ. Influence of supplementary vitamins, minerals and essential fatty acids on the antisocial behaviour of young adult prisoners. Randomized placebo-controlled trial. Br J Psychiatry 2002; 181: 22-8.

3 McCann D, Barrett A, Cooper A, Crumpler D, Dalen L, Grimshaw K, et al. Food additives and hyperactive behaviour in 3-year-old and 8/9-year-old children in the community: a randomised, double-blinded, placebo-controlled trial. Lancet 2007; 370: 1560-7

4 Hibbeln JR, Nieminen LRG, Lands WEM. Increasing homicide rates and linoleic acid consumption among five western countries, 1961-2000. Lipids 2004; 39: 1207-13.

5 Liu J, Raine A, Venables A, Sarnoff AM. Malnutrition at age 3 years and externalizing behavior problems at ages 8, 11, and 17 years. Am J Psychiatry 2004; 161: 2005-13.

6 Fairchild G, Goozen SH, Stollery SJ, Aitken MR, Savage J, Moore SC, et al. Decision-making and executive function in male adolescents with early-onset or adolescence-onset conduct disorder and control subjects. Biol Psychiatry 2009; 66: 162-8.

7 Benton D. The impact of diet on anti-social, violent and criminal behaviour. Neurosci Biobehav Rev 2007; 31: 752-74.

8 Turner CF, Ku L, Rogers SM, Lindberg LD, Pleck JH, Sonenstein FL. Adolescent sexual behavior, drug use, and violence: increased reporting with computer survey technology. Science 1998; 280: 867-73.

9 Rutter M, Whitmore K, Tizard J. Education, Health and Behaviour. Longmans, 1970.

10 Batty GD, Deary IJ, Schoon I, Gale CR. Mental ability across childhood in relation to risk factors for premature mortality in adult life: the 1970 British Cohort Study. J Epidemiol Community Health 2007; 61: 997-1003.

11 Fabrigar LR, Wegener DT, MacCallum RC, Strahan EJ. Evaluating the use of exploratory factor analysis in psychological research. Psychol Methods 1999; 4: 272-99.

12 King G, Zeng L. Logistic regression in rare events data. Polit Anal 2001; 9: 137-63. 